\title{
Research on High Pressure Die Bulging to Helicoid Surface of Metal Helical Stator
}

\author{
Shuqiang Wang ${ }^{1, *}$, Jinmeng Qiao ${ }^{2}$, Dan Sun ${ }^{3}$ and Bilal Akram ${ }^{1}$ \\ ${ }^{1}$ Mechanical School of Shenyang University of chemical technology, Shenyang, China \\ ${ }^{2}$ Bluestar (Beijing) Chemical Machinery Co. Ltd, Beijing, China \\ ${ }^{3}$ North Huajin chemical industries group corporation, Panjin, China \\ ${ }^{*}$ Corresponding author
}

Keywords: Helicoid surface, High pressure Die bulging, Finite element analysis.

\begin{abstract}
As to high pressure bulging of spiral stator metal tube with equal thickness rubber bushing, the paper proposing a method of internal and external high pressure bulging which charactered by the diameter of the rough tube is between the major diameter and the minor diameter of the spiral surface of the tube. It formes the groove part of the tube and the convex part of the tube by external high pressure bulge and internal high pressure bulge respectively, so it reduces the limit height of expansion to the thickness and geometric size of the workpiece. The simulation of bulging process is carried out by using finite element software, reveals the forced flow law of metal pipe under the contact of uniform high pressure and regular spiral surface and verifies the feasibility of internal and external high pressure bulging process, this method can greatly reduce the pressure of bulging system.
\end{abstract}

\section{Introduction}

Screw drilling tool has been widely used in petroleum industry. It is a very special screw machine and widely used in drilling process. The traditional screw drilling tool stator is composed of cylindrical metal pipe and rubber helix surface with different wall thickness[1]. The metal stator with equal wall thickness rubber layer is a kind of different structure product developed in recent years in petroleum machinery, the rubber layer with equal wall thickness is generated by injecting glue into the inner wall of the metal stator premachined with an inner spiral surface, this stator with the equal wall thickness rubber layer makes the screw drilling function greatly improved.

In this paper, the internal spiral surface of metal stator is machined by hydraulic filling mold bulging method, the internal and external step filling die bulging process are proposed. Hydraulic bulging technology is a flexible machining technology which takes liquid as force transfer medium and makes use of liquid pressure and axial thrust to deform tube billet into parts of special shape. At present, the hydraulic bulging machining technology and theoretical research are mainly aimed at the internal high-pressure forming of thin-walled pipe fittings, and the research on external high pressure forming of pipe fitting especially thick wall pipe fitting started later. Before we put forward the internal high pressure filling mould bulging process to realize its processing and manufacturing, other scholars have studied the high-pressure forming method of metal stator bushing, establishing the high pressure numerical model of large aspect ratio helical curved metal stator bushing, K Siegertk of the University of Stuttgart have studied the forming of external high pressure and carried out computer simulation and experiment, considering that the working pressure of external high pressure forming is much lower than that of internal high pressure forming[2].

\section{Principle of Internal and External High Pressure Bulging of Spiral Curved Surface}

High pressure bulging in pipe is to inject liquid into the inner part of tube billet to bulge, apply high pressure loads sealed by the punches at both ends of the tube billet, and apply axial feeding force to pressure the pipe to fill the material, under the interaction of two kinds of pressure loads the billet is 
plastically deformed. The inner surface of the billet and die is pasted to obtain the required geometric shape and dimensional precision. External high pressure bulging is a kind of forming process which uses high pressure liquid to apply working pressure on the outer part of closed hollow tube billet to make the section of tube billet smaller and to attach mould to the outer surface of pipe billet to obtain a certain forming precision. The schematic diagram of internal and external high pressure bulging is shown in figure 1.

Internal and external high pressure bulging is that the tube is bulged out of the groove part through the external high pressure device, and then the formed pipe tube bulges out of the bulge part through the internal high pressure device, the billet tube forming height and system forming pressure are greatly reduced by internal and external step bulging process.
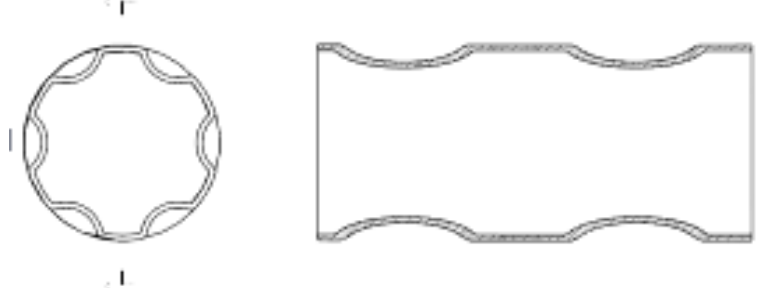

(a)workpiece after external high pressure bulging
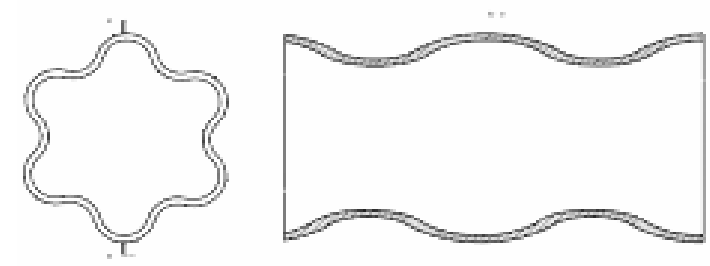

(b)workpiece after internal and external high pressure bulging

Figure 1. Internal and external progressive die filling bulging method

\section{Simulation of Hydro-forming Process of Metal Stator Bushing}

The 3d model and finite element model of workpiece and mold are established. The lead of helix surface is $960 \mathrm{~mm}$, The inner mold diameter is $126 \mathrm{~mm}$, the small diameter is $110 \mathrm{~mm}$, the groove depth is $8 \mathrm{~mm}$, the outer mold diameter is $142 \mathrm{~mm}$, the small diameter is $126 \mathrm{~mm}$, the groove depth is $8 \mathrm{~mm}$. the length of both inner and outer mold is $100 \mathrm{~mm}$. Selecting of 45 \# Steel as forming Pipe material, model length is $102 \mathrm{~mm}$. The mechanical properties of the workpiece are shown in Table 1.

Table 1. Mechanical properties parameter list of tube blank

\begin{tabular}{cccc}
\hline Density[kg/m $\left.{ }^{3}\right]$ & Modulus of elasticity [MPa] & Poisson ratio & Yield limit[MPa] \\
\hline 7850 & $2.1 \mathrm{e} 5$ & 0.31 & 355 \\
\hline
\end{tabular}

(1) Element selection: The workpiece adopts thin shell unit SHELL163 unit. It's a 4-node unit and has film and bending properties and can load normal and plane loads. Both internal and external molds use SOLID164 unit which is a three-dimensional solid unit.

(2) Grid division: The inner and outer molds are of complex spiral shapes using free mesh. The tube billet is a regular model, using mapping network.

(3) Contact setting: The contact type of the workpiece and the mold as one side automatic contact. Automatic contact allows contact to occur on either side of the shell element taking into account the thickness of the shell. The friction coefficient to 0.05 as the average friction coefficient between the pipe and the die.

(4) Boundary condition: The die is set as a fixed constraint, and both ends of the workpiece beyond the part of the die apply a z-direction displacement constraint, in the process of external high pressure bulging. Radial and uniform liquid pressure to the surface of the workpiece are added.

(5) Solution and post-processing: The solution time, result file type and the number of steps after the output of the file can be solved with Solve.The solution results in the processor can be viewed.

The finite element models of the external high pressure bulging phase and the internal high pressure bulging phase are shown in figure 2(a),(b)respectively. 


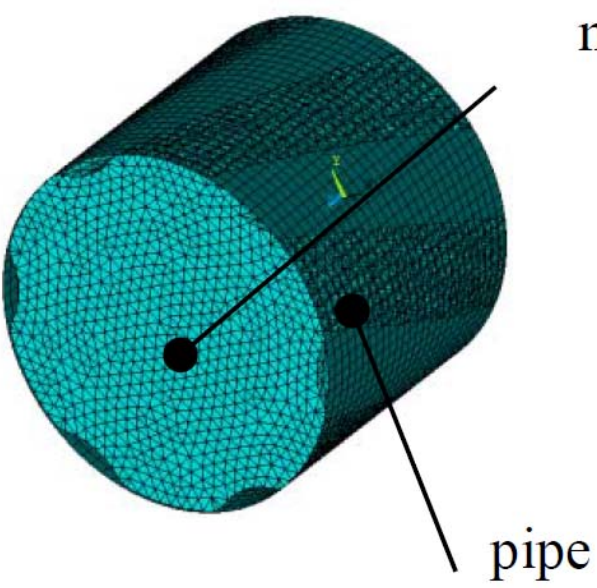

(a)

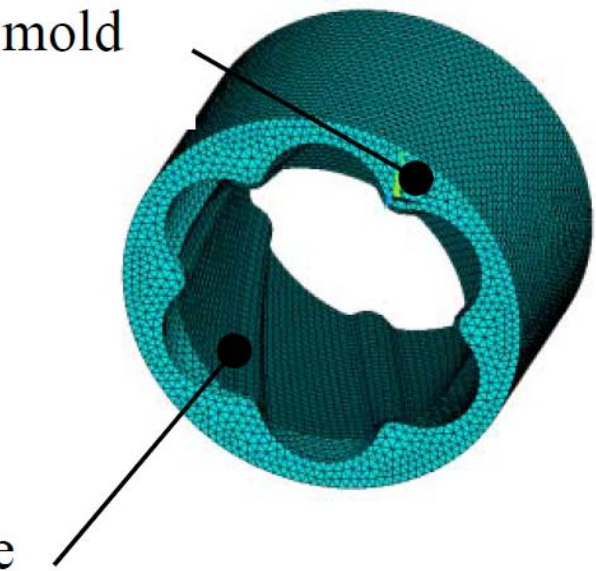

(b)

Figure 2. Finite element model of internal and external high pressure bulging process

(a) Finite element model of external high pressure bulging (b)Finite element model of internal high pressure bulging

\section{Simulation Result}

\section{Comparison of the Effects of Mold Mounting}

Workpiece bulging pressure should meet the requirements to ensure the shape of the screw and the workpiece better stick die. The bulging pressure adopts the bilinear loading curve, the wall thickness of the pipe is $4 \mathrm{~mm}$. Fig. 4 (a), (b), (c) shows the deformation of a fixed cross-section pipe under internal high pressure, external high pressure, and internal and external step-by-step pressure with the same bulging pressure as 140Mpa.
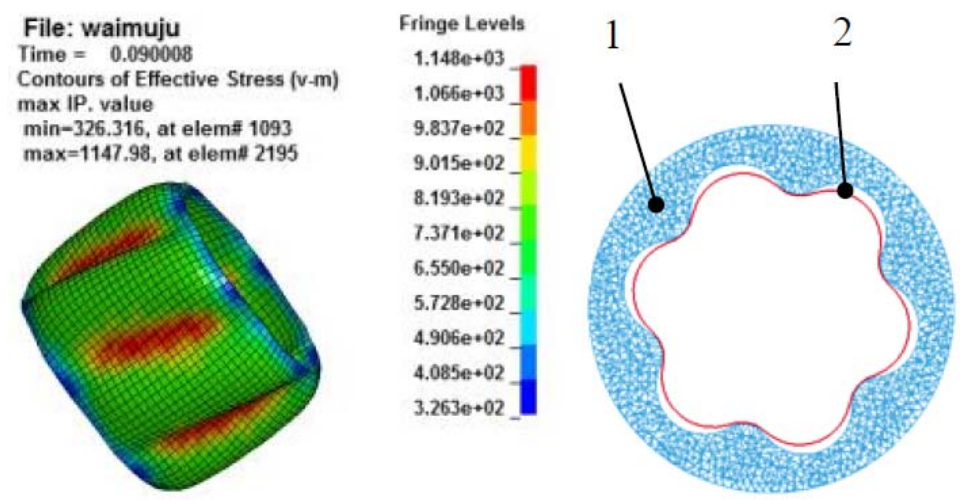

(a) Tube formed by internal high pressure bulging
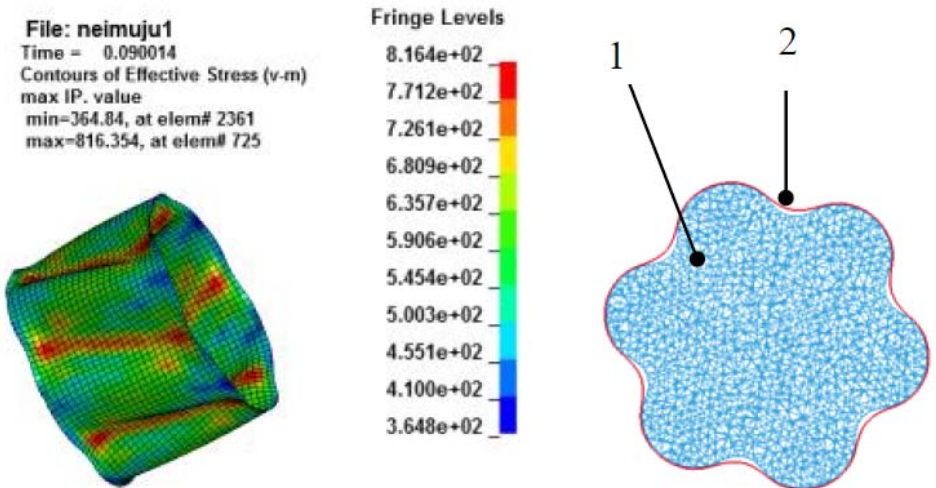

(b)Tube formed by external high pressure bulging 


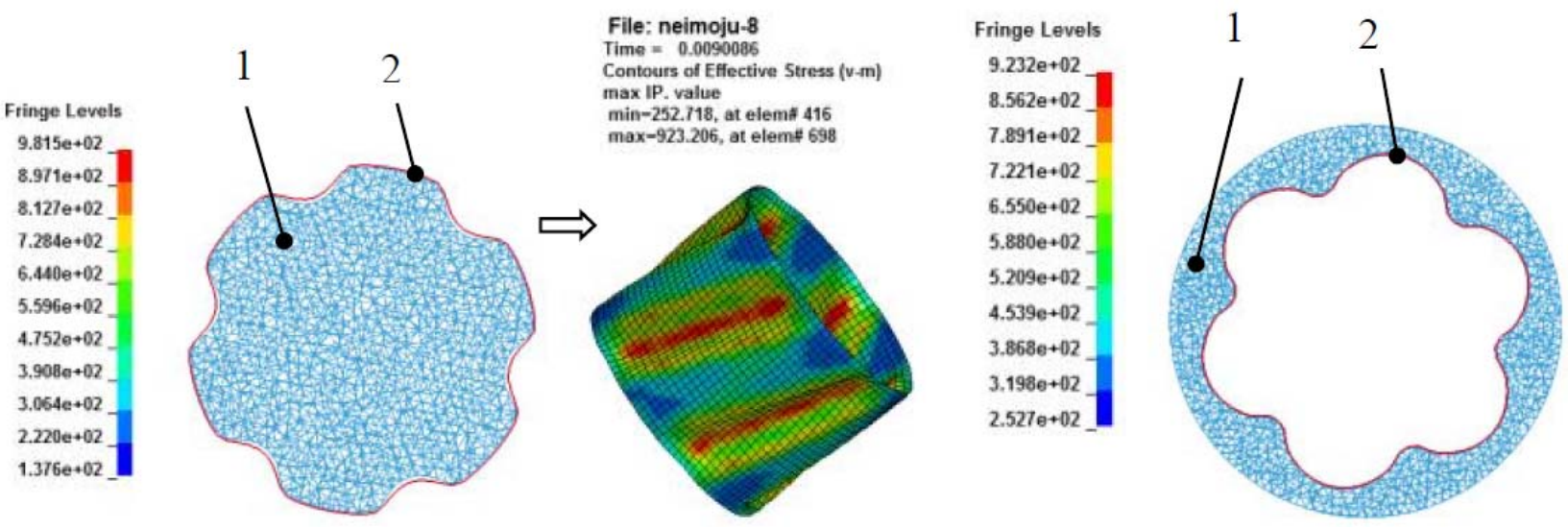

(c) Tube formed by internal and external high pressure bulging

Figure 3. Tube formed by high pressure bulging 1-mold 2-workpiece

It can be seen that the pressure required by external high-pressure forming is lower than that required by internal high-pressure forming, while the pressure required by internal and external stepwise high-pressure forming is lower than that required by external high-pressure forming. The internal and external step filling die bulging process can greatly reduce the pressure of bulging system and the limit height of bulging limit to the thickness and geometric size of workpiece.

\section{Maximum Deformation Displacement}

Under the load of different liquid pressure, the curve of the maximum deformation displacement of internal and external step-by-step bulging is shown in Fig. 4.

With the increase of the internal maximum hydraulic pressure, the maximum radial displacement of the workpiece also increases. However, the hydraulic pressure cannot be increased unlimitedly because the maximum stress of the billet should not exceed the tensile limit of the material.

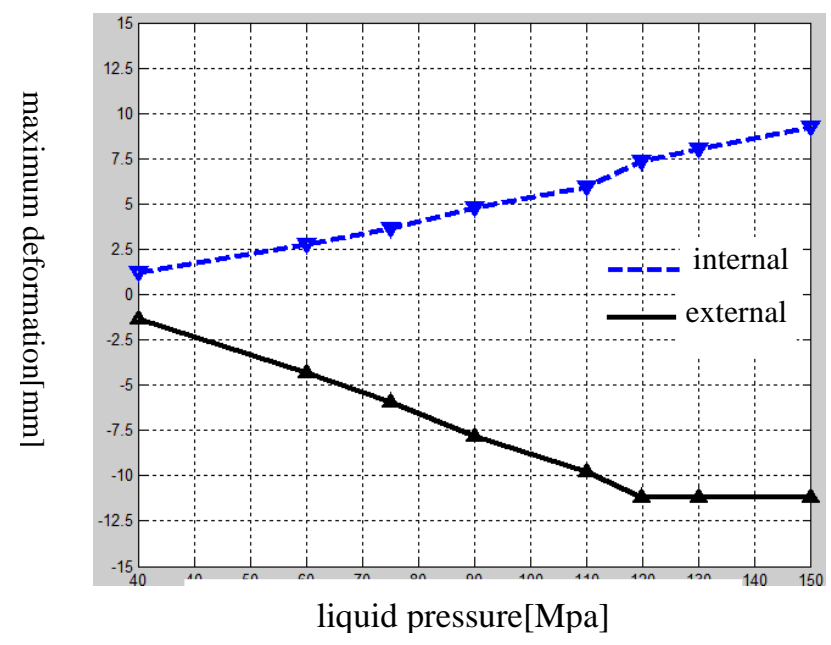

Figure 4. Maximum deformation displacement curve under different hydraulic pressure loads

\section{Effect of Wall Thickness on Forming}

When the blank fitting fits well with the mold, the bulging pressure of the tube with different wall thickness is different, for the billet with different wall thickness, the maximum internal hydraulic pressure of $80 \mathrm{MPa}$ is adopted and the other constraint conditions are the same. the effect of wall thickness on bulging law is studied through the simulation results. Fig. 5 shows the displacement curves of pipe fittings with different thickness.

When the maximum hydraulic pressure is the same, the maximum deformation displacement of the workpiece decreases with the increase of wall thickness. However, the wall thickness of the workpiece should not be too small, the wall thickness of the workpiece and the pressure of the system 
should be combined optimally, and it is easy to break the tube billet in the process of bulging when the wall thickness is too small.



Figure 5. Maximum forming displacement curve of tube blank with different wall thickness

\section{Summary}

A new method of internal and external split-step high-pressure bulging of spiral stator metal tube with equal wall thickness is presented. The diameter of the blank pipe is between the large warp diameter of the fitting spiral surface and the small diameter of the fitting spiral surface. The external high pressure bulge forms the groove part of the tube and the internal high pressure bulge forms the bulge part of the shape pipe.

The influence of forming force and wall thickness on forming by finite element method are analyzed. It is verified that the internal and external step filling die bulging process can greatly reduce the pressure of bulging system and reduce the limit height of bulging to the thickness and geometric size of the workpiece. The simulation results are verified by the experiment of bulging. It provides support for further optimization of bulging process parameters.

\section{Acknowledgement}

This research was financially supported by the Liaoning Natural Science Foundation (20170540722).

\section{References}

[1] Zheng H L, Guo G L, Jian L. Stator structure design and mechanical analysis of a new type of screw drilling tool with equal wall thickness[J].Petroleum Field Machinery, 2011, 40(8): 74-77.

[2] K.Sieger.t Research in Hydroforming at the Institute of Metal Forming Technology of the University of Stuttgart[C]. 3rd International Conference on Hydroforming. Stuttgart, 2001: 245 -258.

[3] Ahmetoglu M, Altan T. Tube hydroforming: state-of-the-art and future trends [J]. Journal of Material Procession Technology, 2000, 98(1): 25-33.

[4] Song X Y, Hui H, Gong J G, et al. Numerical analysis and experimental research on hydroforming of corrugated tubes [J]. Journal of Plasticity Engineering, 2017, 24 (6) : 68-73.

[5] Abdel Hakim Ben Ouirane, Raphael Velasco. Error evaluation on experimental stress-strain curve[J]. Int J Mater, 2010, 3: 195-198.

[6] Deng J, Shi C S. Study on hydroforming method of staiess Steel stator bushing with large aspect rationl[J].Hot working technology, 2017, 46(17):146-150. 